\title{
Normal Blood Test Result
}

National Cancer Institute

\section{Source}

National Cancer Institute. Normal Blood Test Result. NCI Thesaurus. Code C35655.

A laboratory test result indicating the results of the blood test are within normal

parameters for the age and population. 